\title{
Research and Practice of Sports Teaching Based on Information Technology and Bilateral W-test
}

\author{
Jingyi $\mathrm{Wu}^{1}$, Yan $\mathrm{Chen}^{1}$, Jingzheng Guo ${ }^{2}$ \\ ${ }^{1}$ Department of Physical Education, Hebei University of Technology, TianJin, China \\ w_u_jingyi@126.com \\ ${ }^{2}$ Finance Department, Hebei Institute of Physical Education, ShiJiaZhuang, China
}

Keywords: information technology; bilateral w-test; test analysis; fidelity; mathematical statistics

\begin{abstract}
With the continuous development of education modernization, modern information technology has been used as an important teaching way in education field, which has also become the main part of modern education. But the application of modern information technology relatively lag behind in the sports teaching, which become a subject concerned by the physical education workers. This paper analyzes the advantages of information technology in sports teaching, and applies information technology in the teaching practice. Then, based on the empirical analysis, the authors make some practice verification on the teaching effect. Finally the authors draw the conclusion that it can optimize the teaching structure by using information technology in sports teaching,which can improve the comprehensive quality of sports students.
\end{abstract}

\section{Introduction}

With the continuous development of information technology, its application scope becomes more and more wide in the teaching field.And the application of information technology becomes more and more mature day after day, which plays an extremely important role in daily teaching and makes positive contributions to promoting the education development. But the application of information technology is bound to the traditional teaching pattern in the sports teaching, whose development has very broad space.There are many researches about that area, such as teaching practice research on how to use modern information technology to optimize sports effect by Lu Weigang, who emphasized that information technology is a new mode of modern teaching.It must be effectively integrated in modern sports teaching $\mathrm{n}$ order to promote the physical education services[1]. According to the previous studies, it is no difficulty to find that the study on this field is quite extensive.There are many researches on the problems that how to use information technology in sports teaching. Most of them are theoretical, however, the practice research is slightly weak[2]. In this paper, based on information technology,sports teaching focuses on time link research and the comparison of teaching results, which provide more scientific and theoretical basis and path for the application of information technology in sports teaching.

\section{The superiority analysis on the application of information technology in sports teaching}

\section{A. The disadvantages of traditional sports teaching}

The disadvantages of traditional sports teaching include the following aspects: (1)the teaching means is single;(2) teaching form lacks change; (3)sports classroom efficiency is not high;(4)the teacher's lesson and expression of knowledge content is limited;(5) the enthusiasm of the students is not high in the teacher-led class. And there are few participation opportunities for students, who are generally passive learning; and teaching content is not abundant enough. Most of the teachers are teaching just in accordance with the teaching plan, not adding some opportunities to expand the relevant knowledge, and the teaching content is only limited to the teaching plan.

B. The advantages of the application of information technology in sports teaching

The application of information technology is an important part in sports teaching for the implementation of education modernization, which applies modern equipment to lead sports teaching reform in order to provide good opportunity for the modernization of sports and promote the informationization construction. The application of information technology is one of teaching factors 
in sports courses, which becomes the tool to construct a sports learning environment[3]. In the process of analyzing the features that how human body accepts information, it is the most easy for the brain to accept sensory stimulation and produce signals. And it can make teaching content more imaginary by using information technology. Let it be similar with the characterization of specific things, so we should pay attention to learning quality and relationship fidelity degree in the process of sports teaching. And the specific relationship is shown in Figure 1.

As shown in Figure 1, in real teaching circumstances, the rendering sine parabolic relationship between visual media and students' learning quality has a direct link with the application of information technology. Information data can make organic combination of the information technology, information resources, information method, teaching content, teaching methods and practice[4]. It can improve the students' information consciousness by making organic combination with teaching and information technology and leading sports teaching toward the optimization direction, which continuously pushes forward the new reform of teaching in the teaching process. The specific process are as the Figure 2 shows.

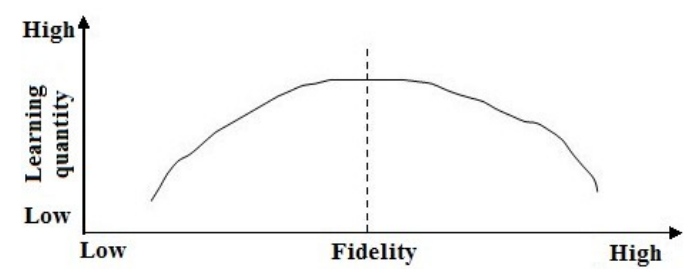

Figure 1. The relationship between learning quality and fidelity degree in sports learning process

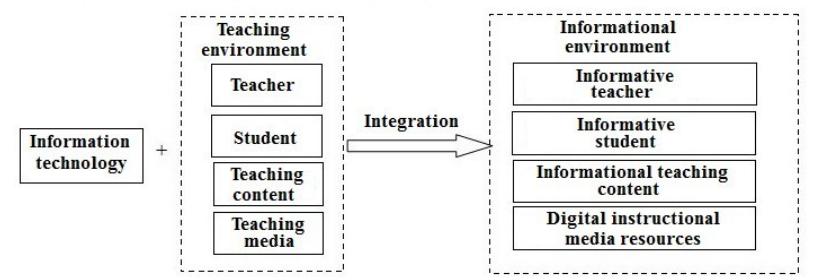

Figure 2. Teaching advantage structure diagram under the condition of information technology

As shown in Figure 2, when information technology is applied bidirectionally in sports teaching, the two integrated relation has presented that the former is the transform of information technology, which includes sports teaching, the developed information technology for education in sports teaching process and the application of information technology in sports teaching. In the actual teaching process, we not only use the information technology as a new teaching media, but also link the information technology with the whole structure in sports teaching. By integrating each of the organic elements, we gradually form the sports teaching method. Compared to the traditional method of cramming teaching, sports teaching will have far-reaching significance based on information technology.

\section{Practice research on sports teaching under the condition of information technology}

The system model of practice process in sports teaching under the condition of information technology

Under the information technology, the sports teacher makes teaching content programmable and passes it to students through information media, which can use the multimedia teaching and construct information teaching system[5]. The teacher not only teaches sports theoretical knowledge, but also solves all sorts of problems and answers the corresponding question through information media. At the same time, the assessment system could conduct evaluation and diagnosis of students' learning effects, which can timely give the feedback of evaluation information to the students. The system model of sports teaching process is shown as below.

As shown in Figure 3, under the condition of information technology, the process system of sports teaching can be seen as an open teaching process. In the whole process, it concludes mining properties, function and physical education development. In sports teaching environment, input part is composed of teachers, teaching content, teaching media, information technology and teaching cognitive component. We could investigate on the following things, such as students' age, their physical condition, students' non-intelligence factor and students' mental status. In furthermore, the output section of whole teaching module refers to the investigation of students' learning attitude, learning behavior, cognition, teaching feedback, learning content and so on. 
The control process of teaching goal in sports teaching under the condition of information technology

Based on information technology in the process of sports teaching, physical education workers is the dissemination of information, students are the recipients of information, information media is the carrier of sports teaching information, and the three factors will be controlled by the teaching target. The relationship is shown in Figure 4.

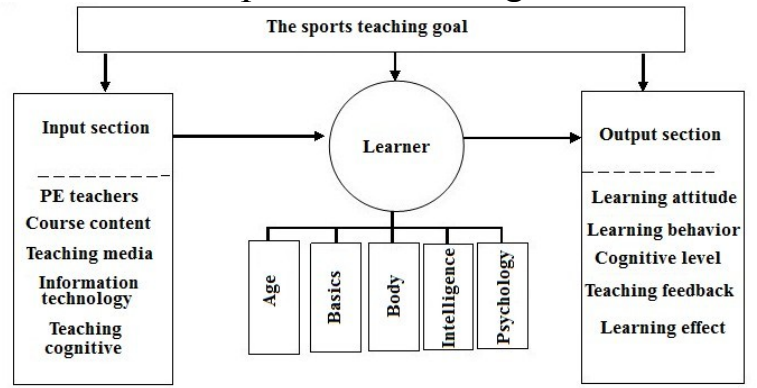

Figure 3. The system model of practice process in sports teaching under the condition of information technology

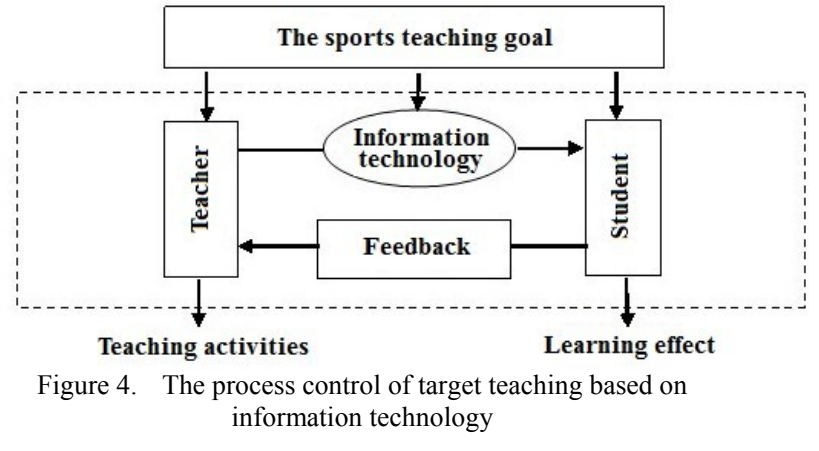

As shown in Figure 4, the whole teaching target control needs general and specific goals in two levels: general teaching goal is the optimized teaching requirements, in which the teaching is based on the objectives of sports teaching, and it make detailed planning target of the branch, which also has some status analysis. The deep analysis of sports teaching principle is shown as below.

As shown in Figure 5, with the support of information technology, to start sports teaching, we should select teaching learning content according to the needs of the students, and use the multimedia technology to present related teaching information. Under the autonomous guide, students can select the study content, put forward corresponding questions in the learning process, and reflect the questions to the teacher[6]. The sports teachers can make corresponding judgment and feedback in the sports classroom. The students further strengthen the feedback problems to give some scientific judgment for the teacher, who can help the students to make further decision. New courses are interspersed in the education information, which could form stepwise cycle between students and teachers. So the target of teaching control will make the optimized final effect.

\section{Teaching practice analysis based on information technology}

In order to get a better sports teaching effect based on information technology, we use the students' excellent rate to evaluate teaching practice effect, which refers to the students whose sports teaching excellent grades greater than 90 , good refers to the sports teaching course grade greater than 80 , in which, excellent refers to sports course grades greater than 90 , medium refers to sports course score greater than 70 .sports teaching course excellence rate is a commonly used statistical methods to measure the effect of sports teaching.

Generally speaking, the practice of physical education teaching can be divided into $\mathrm{n}$ projects, excellent rate of each project $\mathrm{i}$ is ${ }^{R_{i}}$, the total utilization rate $\mathrm{R}$ can be calculated by the following formula[7]: $\quad R=\sum_{i=1}^{n} a_{i} R i$ (1)

In which, ${ }^{a_{i}}$ meets $0 \leq{ }^{a_{i}} \leq 1$, and $\sum_{i=1}^{n} a_{i}=1$ is the weight coefficient. In the sports teaching practice, in order to do better teaching practice with comprehensive, system, clear understanding of information technology, providing a scientific basis for the research on sports teaching under the information technology. In the sports teaching, among the freshman class, class 1 is the experimental class, class 2 is the reference class one semester's teaching, the student distribution proportion are shown in the following table 1. 
TABLE I. THE TEACHING OBJECT TABLES OF SPORTS TEACHING PRACTICE

\begin{tabular}{|c|c|c|c|}
\hline Gender & Proportion & $\begin{array}{c}\text { Class } 1 \\
\text { ( experimental class) }\end{array}$ & $\begin{array}{c}\text { Class } 2 \\
\text { (reference class) }\end{array}$ \\
\hline \multirow{2}{*}{ Boys } & The number of students & 36 & 35 \\
\hline & The ratio $\%$ & $54.55 \%$ & $52.23 \%$ \\
\hline \multirow[b]{2}{*}{ Girls } & The number of students & 30 & 32 \\
\hline & The ratio $\%$ & $45.45 \%$ & $47.76 \%$ \\
\hline Total & The number of students & 66 & 67 \\
\hline
\end{tabular}

As shown in Table 1, two class numbers are equal, men and women are equal too, the experimental class conduct teaching practice badly on information technology, the original reference class according to the teaching plan in traditional teaching practice. The specific training programs include broadcast gymnastics, sports five all-around, basketball etc. The total outstanding rate for sports practice is[8]: $\quad a_{1} R_{1} a_{2} R_{2} a_{3} R_{3} a_{n} R_{n}$

$a_{1} 、 a_{2} 、 a_{3} \ldots . . .{ }^{a_{n}}$ are broadcasting gymnastics, sports five all-around, basketball, weight coefficient;

$R_{1} 、 R_{2} 、 R_{3} \ldots \ldots R_{n}$ are excellent rates of broadcasting gymnastics, basketball, sports five allaround.

For each item, if the i can be subdivided into more small items, then need subclasses for i project and decomposition of $\mathrm{k}, R_{j}^{(i)}$ is the excellent rates of the $\mathrm{j}$ subclass in i project, such as sports five allaround may be further subdivided into five small projects. Then we can get the formula[9]:

$$
R_{j} \sum_{J=1}^{K} a_{j}^{(j)} R_{J}^{(J)}
$$

In the formula (2), $0 \leq^{a_{j}^{(i)}} \leq 1, \sum_{j=1}^{k} a_{j}^{(i)}=1$, after a semester teaching, conduct the final sports test performance statistics of the experimental class and the control version, and analyze the proportion of correlation, the results show that, the sports teaching practice based on information technology have significant results, the statistical results are shown in the below diagram.
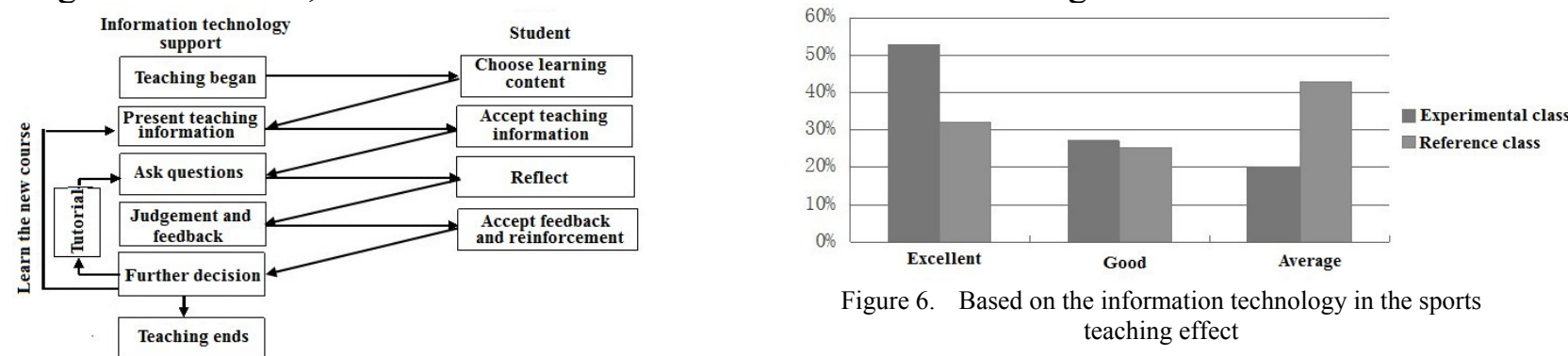

Figure 6. Based on the information technology in the sports teaching effect

Figure 5. The principle diagram of sports teaching practice under the condition of information technology

As shown in Figure 6, the excellent rate in the experimental class is significantly higher than the reference class. Among which, there are $53 \%$ of students achieve outstanding performance in experimental class. Compared to the reference class' $32 \%$, it increases by $20 \%$; the number of students achieving good level in experimental class is also higher than that of the reference class. It can be explained that is feasible for the application of information technology in sports teaching, which can significantly improve the teaching effect. In a subsequent interview survey of teachers, teachers tend to use information technology in sports teaching. The application of information technology can optimize the teaching structure in sports teaching and improve the comprehensive quality of students in sports.

\section{Conclusion}

With the reform of modern teaching pattern, information technology is bound to apply in various disciplines teaching. This technology has also brought great convenience to sports teaching. Compared with traditional teaching, the sports teaching has great advantages based on information 
technology. In the practical teaching link, the sports teaching should absorb multimedia teaching and the advantages of traditional teaching.

\section{References}

[1] Lu Weigang.Research on the use of modern information technology to optimize the physical education teaching practice.China Information Technology Education,2010(24):13-14

[2] Gu Hongfei.Some problems and analysis on the application of modern information technology in sports teaching practice. Modern education technology,2009(4) : 23-25

[3] Zhang Zhenjie.Exploration and practice of sports teaching mode under the environment of information.China Information Technology Education,2009(24):41-42

[4] Liu Meijin.Case teaching practice of information technology and sports teaching.China Information Technology Education,2009(19):61-62

[5] Gap Feifei.The problems and countermeasures for the combination of information technology and college sports teaching.Journal of Shanxi University of Technology (Social Sciences),2010(04):32-33

[6] Zhang Youlu.University Modern Education Technology Course.China Railway Press,2011:8990

[7] Wang Zonfeng.Information technology and physical education teaching.Glorious chapter(Teaching exploration),2010(2):45-47

[8] Hu Xiaoqiang.Modern education technology.Beijing:Beijing University Press,2012:102-103

[9] Guo Qiong.Modern education technology.The people post and Telecommunications Press,2012:132-134 